\title{
Article \\ Correlation of EDLC Capacitance with Physical Properties of Polyethylene Terephthalate Added Pitch-Based Activated Carbon
}

\author{
Cheol Hwan Kwak ${ }^{1}$, Dohwan Kim ${ }^{2}$ and Byong Chol Bai ${ }^{3, *}$ \\ 1 Institute of Carbon Fusion Technology (InCFT), Chungnam National University, Daejeon 34134, Korea; \\ kwakch@cnu.ac.kr \\ 2 Strategic Planning Division, Korea Institute of Convergence Textile, Iksan 54588, Korea; \\ sunriselloll@gmail.com \\ 3 Division of Energy Engineering, Daejin University, Pocheon 11159, Korea \\ * Correspondence: baibc0820@daejin.ac.kr
}

check for

updates

Citation: Kwak, C.H.; Kim, D.; Bai, B.C. Correlation of EDLC Capacitance with Physical Properties of Polyethylene Terephthalate Added Pitch-Based Activated Carbon.

Molecules 2022, 27, 1454. https://

doi.org/10.3390/molecules27041454

Academic Editors: Abhishek K.

Mishra, Yogendra Kumar Mishra and

Rasoul Khaledialidusti

Received: 18 January 2022

Accepted: 19 February 2022

Published: 21 February 2022

Publisher's Note: MDPI stays neutral with regard to jurisdictional claims in published maps and institutional affiliations.

Copyright: (c) 2022 by the authors. Licensee MDPI, Basel, Switzerland. This article is an open access article distributed under the terms and conditions of the Creative Commons Attribution (CC BY) license (https:// creativecommons.org/licenses/by/ $4.0 /)$.

\begin{abstract}
The electric double-layer capacitor (EDLC) has attracted attention by using activated carbon (AC) as an active electrode material with a high power density and high cost-efficiency in industrial applications. The EDLC has been actively developed over the past decade to improve the power density and capacitance. Extensive studies on EDLCs have been conducted to investigate the relation of EDLC capacitance to the physical properties of AC, such as the specific surface area, pore type and size, and electrical conductivity. In this study, EDLC was fabricated with AC, and its capacitance was evaluated with the physical properties of AC. The AC was prepared using petroleum-based pitch synthesized using pyrolysis fuel oil (PFO) with polyethylene terephthalate (PET). The AC based on PFO and PET (PPAC) exhibited high specific surface area and low micropore fraction compared to the PFO-based AC without PET addition (PAC). Furthermore, the reduction of the EDLC capacitance of PPAC was smaller than that of PAC, as the scan rate was increased from 5 to $100 \mathrm{mV} \mathrm{s}{ }^{-1}$. It was determined that the minor reduction of capacitance with an increase in the scan rate resulted from the development of $4 \mathrm{~nm}$-sized mesopores in PPAC. In addition, a comprehensive correlation of EDLC capacitance with various physical properties of ACs, such as specific surface area, pore characteristics, and electrical conductivity, was established. Finally, the optimal properties of AC were thereupon derived to improve the EDLC capacitance.
\end{abstract}

Keywords: petroleum residue; pitch; PET; activated carbon; EDLC; capacitance

\section{Introduction}

Interest in electric energy storage has recently grown due to mobile electronics and electric vehicles. Consequently, the demand for energy storage materials such as lithium-ion batteries (LIBs) and electric double-layer capacitors (EDLCs) is increasing [1-3]. Numerous studies have been conducted in the past 20 years to improve the high-power density, long cycle life, and capacity of EDLCs [4]. An EDLC stores energy by reversible adsorption and desorption of ions at the electrolyte-electrode interface rapidly, showing a high-power density [5]. In other words, it can produce high power in a short period and thus can be utilized in various electronics such as mobile phones, camera flashes, and electric vehicles. However, it has low energy density because of its limited surface to store ions [6].

A significantly activated carbon (AC) material is most commonly used as an EDLC electrode material. The AC with high conductivity and specific surface area is therefore required to improve the power density and capacity of EDLCs [5]. Recently, AC was obtained by carbonizing waste from fiberboard (medium density) at $500{ }^{\circ} \mathrm{C}$. Activation was performed using $\mathrm{KOH}$ activation agents at $800{ }^{\circ} \mathrm{C}$ with various $\mathrm{KOH} /$ coke mass ratios. Micropores and mesopores could be obtained with specific surface areas above $1500 \mathrm{~m}^{2} \mathrm{~g}^{-1}$. Specific capacitances ranging over $200 \mathrm{~F} \mathrm{~g}^{-1}$ were obtained for the AC electrode. There are design strategies that can improve the energy density of supercapacitors to 
improve the capacitance and long cycling stability of EDLC materials. A variety of material combinations allow the high capacitance of materials to be exploited. Porous carbon, such as AC materials, can be wisely selected to improve the operating voltage window and the cell's capacitance, and the pseudocapacitive material acts as an electrode that does not show redox contribution and low stability [5]. Previous studies have found that an increase in specific surface area to a certain level improves the capacitance of EDLC. Still, an increase in specific surface area beyond that level decreases the capacitance due to a reduction of conductivity by micropores [7]. In addition, the adsorption behavior of ions depends on the size of the pores. For example, it was observed in a previous study that an EDLC based on AC with 2-5 $\mathrm{nm}$ pores size showed high capacitance [8,9].

Various studies on the relationship of the capacitance to the specific surface area, the electrical conductivity, and the volume of $2-5 \mathrm{~nm}$ size of micropores were already performed [10-16]. However, studies have not been conducted to analyze the overall relationship between the factors listed above that affect capacitance. The specific surface area, pore characteristics, and electrical conductivity of AC are closely related. More specifically, as micropores develop, the specific surface area increases, and the electrical conductivity decreases $[17,18]$. Therefore, when comparing the properties of AC and the capacitance of an AC-based EDLC, analyzing only one property does not significantly contribute to research on improving the EDLC properties and industrial applications.

Most commercially available devices that use AC as an electrode material operate at a cell voltage of $2.7 \mathrm{~V}$. Specific capacitances of 100 to $120 \mathrm{~F} \mathrm{~g}^{-1}$ and volumetric capacitances up to $60 \mathrm{~F} \mathrm{~cm}^{-3}$ have been reported $[19,20]$. Electrodes using an aqueous electrolyte had a limited cell operating voltage of up to $0.9 \mathrm{~V}$ [21] and a specific capacitance value of $300 \mathrm{~F} \mathrm{~g}^{-1}$ [22]. Past research has focused on the use of three types of AC monoliths as electrodes in half-cell electrochemical systems. The porosity and surface area were improved due to grain formation during oxidation. The maximum capacitance values obtained were $27.68 \mathrm{~F} \mathrm{~g}^{-1}, 2.23 \mathrm{~F} \mathrm{~g}^{-1}$, and $1.20 \mathrm{~F} \mathrm{~g}^{-1}$ for acid, vapor-oxidized, and non-oxidized electrodes, respectively [23]. According to the report, an energy density of 1.27 $\mathrm{Wh} \mathrm{kg}^{-1}$ and a specific capacitance of $100 \mathrm{~F} \mathrm{~g}^{-1}$ were obtained for the graphenegold nanoparticle composite. In one paper, graphene-based carbon with high porosity was fabricated. The carbon obtained gave rise to a Brunauer-Emmett-Teller (BET) surface area of up to $3290 \mathrm{~m}^{2} \mathrm{~g}^{-1}$ values. The resulting specific capacitances were $174 \mathrm{~F} \mathrm{~g}^{-1}$ and $\sim 100 \mathrm{~F} \mathrm{~cm}^{-3}$. The observed gravimetric energy and power density values were $74 \mathrm{Wh} \mathrm{kg}^{-1}$ and $338 \mathrm{~kW} \mathrm{~kg}^{-1}$, respectively, and the volume values were $44 \mathrm{Wh} \mathrm{L}^{-1}$ and $199 \mathrm{~kW} \mathrm{~L}^{-1}$, respectively $[24,25]$.

In this study, the petroleum pitch was prepared using pyrolysis fuel oil (PFO) with heat treatment using polyethylene terephthalate (PET). To control the characteristics of petroleum pitch, studies on the air-blowing process and synthesis using additives such as polyethylene and polystyrene have been researched [26-28]. Air-blowing is a polymerization method by which oxygen is added to form crosslinking sites between molecules in the pitch. Blanco et al. have reported that moderate oxygenation improves mesophase content and thermal properties such as softening point and carbon value [29]. However, since the air blowing process requires a long reaction time of $10 \mathrm{~h}$ or more, there is a limit in productivity in a commercial operation. Since PET is synthesized from terephthalic acid and ethylene glycol, it forms chemical substances with oxygen functional groups such as hydroxyl groups and carboxylic acids during thermal decomposition [30,31]. These chemicals promote the polymerization of petroleum pitch, and oxygen also provides crosslinking sites during pitch synthesis [32]. Therefore, pitch synthesis using PET as an additive can achieve similar effects to air-blowing despite a short reaction time.

This study evaluated the specific capacitance of EDLCs fabricated using petroleum pitch-based AC electrodes. To analyze the effect of PET addition to pitch on the specific surface area, pore characteristics, and electrical conductivity of the AC, the correlation of capacitance with these properties of $\mathrm{AC}$ was investigated. As a result, the specific surface area and pore volume of AC based on PFO and PET (PPAC) were improved in comparison 
with those of PFO-based AC (PAC) [26]. It is known that the capacitance is strongly affected by the specific surface area and pore characteristics of AC [33]. In other words, the addition of PET has a significant influence on capacitance. Furthermore, 2-5 nm pores, which significantly affect capacitance, are concerned with changes at different scan rates. However, the electrical conductivity of AC has a negligible effect on the capacitance. Finally, the correlation between the capacitance and four AC factors was analyzed to optimize the pore properties and specific surface area of AC for EDLC production: BET surface area, micropore volume, pore volume at $2-5 \mathrm{~nm}$, and electrical conductivity of AC.

\section{Results}

\section{Capacitance of EDLC Fabricated with Pitch-Based AC}

EDLC electrodes were manufactured using AC prepared from pitch samples synthesized under various conditions. The pitch was first synthesized using PFO and then activated to prepare AC. The results of measuring the CV curve of EDLC fabricated using these ACs are shown in Figure 1. The CV was measured at a scan rate of $100 \mathrm{mV} \mathrm{s}^{-1}$ in a potential window from -1.0 to $-0.2 \mathrm{~V}$ (vs. $\mathrm{Hg} / \mathrm{HgO})$. The $\mathrm{CV}$ curves showed a quasi-rectangular shape.
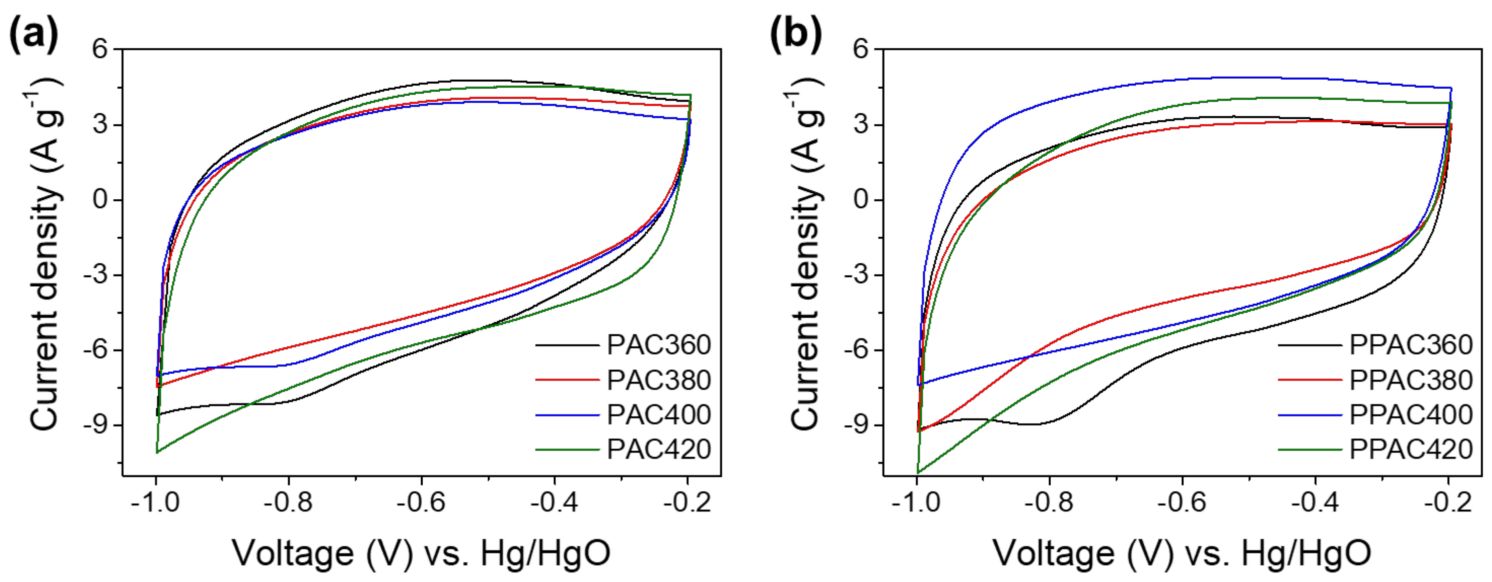

Figure 1. CV curves of EDLC fabricated with electrodes based on (a) PAC and (b) PPAC prepared by various pitch samples.

The capacitance $(C)$ was calculated by the following equation [34].

$$
C=\frac{\int I d V}{M_{e} \times v \times \Delta V}
$$

here, $\int I d V$ is the area of the CV curve, $M_{e}$ is the mass of the active material used, $v$ is the scan rate, and $\Delta V$ is the potential window. The capacitance is calculated from the $\mathrm{CV}$ curve measured at various scan rates in the range of $5-100 \mathrm{mV} \mathrm{s}^{-1}$ and is shown in Table 1. It was confirmed that the capacitance of PPAC was about $87.8-96.9 \%$ of the capacitance maintained compared to PAC prepared at the same pitch synthesis temperature.

In addition, the retention rate of the capacitance was checked when the scan rate increased. The capacitance retention rate is obtained by calculating the capacitance maintained when the scan rate increases from $5 \mathrm{mV} \mathrm{s}^{-1}$ to $100 \mathrm{mV} \mathrm{s}^{-1}$. When comparing pitch-based activated carbon synthesized at the same temperature, the PPAC capacitance was $2 \%$ higher than the PAC sample. When the activated carbon was manufactured using pitch added with PET, it was confirmed that the change in capacitance according to the scan rate was negligible. This phenomenon was believed to be related to the pore characteristics of the activated carbon, and the pore characteristics of the activated carbon were also analyzed. 
Table 1. Various specific capacitance at different scan rates from $5 \mathrm{mV} \mathrm{s}^{-1}$ to $100 \mathrm{mV} \mathrm{s}^{-1}$.

\begin{tabular}{|c|c|c|c|c|c|c|}
\hline \multirow{2}{*}{ Sample } & \multicolumn{5}{|c|}{ Specific Capacitance at Different Scan Rate $\left(\mathrm{F} \mathrm{g}^{-1}\right)$} & \multirow{2}{*}{$\begin{array}{c}\mathrm{C} v_{100} / \mathrm{C} v_{5}{ }^{\mathrm{a}} \\
(\%)\end{array}$} \\
\hline & $5 \mathrm{mV} \mathrm{s}^{-1}$ & $10 \mathrm{mV} \mathrm{s}^{-1}$ & $20 \mathrm{mV} \mathrm{s}^{-1}$ & $50 \mathrm{mV} \mathrm{s}^{-1}$ & $100 \mathrm{mV} \mathrm{s}^{-1}$ & \\
\hline PAC360 & 280.0 & 261.4 & 229.5 & 191.9 & 159.9 & 57.1 \\
\hline PAC380 & 228.2 & 211.3 & 180.8 & 151.5 & 130.2 & 57.1 \\
\hline PAC400 & 222.0 & 216.2 & 191.7 & 165.2 & 144.7 & 65.2 \\
\hline PAC420 & 303.3 & 253.1 & 211.5 & 290.9 & 161.5 & 53.2 \\
\hline PPAC360 & 247.3 & 250.7 & 218.4 & 176.7 & 152.6 & 61.7 \\
\hline PPAC380 & 193.9 & 187.4 & 169.4 & 141.0 & 114.4 & 59.0 \\
\hline PPAC400 & 200.3 & 215.2 & 192.0 & 162.6 & 140.2 & 70.0 \\
\hline PPAC420 & 255.9 & 234.2 & 208.7 & 173.9 & 144.2 & 56.4 \\
\hline
\end{tabular}

${ }^{\text {a }} \mathrm{C} v_{100} / \mathrm{Cv}_{5}$ : Ratio of capacitance at $100 \mathrm{mV} \mathrm{s}^{-1}$ to that at $5 \mathrm{mV} \mathrm{s}^{-1}$.

\section{Discussion}

\subsection{Effect of Specific Surface Area and Porosity of AC on EDLC Capacitance}

Since the specific surface area, pore characteristics, and conductivity of activated carbon are not independent and influence each other, the influence on the relationship and capacitance of each character should be comprehensively analyzed. Table 2 shows the specific surface area, pore characteristics, and conductivity analysis results of the pitchbased activated carbon prepared in this study. The physical properties of activated carbon changed depending on the synthesis temperature of the pitch used as raw material and the presence or absence of PET. In particular, the specific surface area of PPAC was higher than that of PAC due to adding PET. The changes in the pitch property and specific surface area of activated carbon according to the addition of PET were reported in previous studies [33]. In short, adding PET when synthesizing the pitch using PFO dramatically increases the thermal stability of the pitch. The increase in thermal stability makes the pitch structurally stable and prevents the pores from being formed and closed by intermolecular realignment when the pore structure is developed due to activation. Therefore, although the pitch was synthesized at the same temperature, PPAC using a high-stability PET-added pitch has a higher specific surface area than PAC. However, the microporosity tended to decrease when PET-added pitch was used. This phenomenon is caused by the high structural stability of the pitch interfering with the formation of micropores by the activation reaction. The microporosity showed a distribution of $88.4-90.0 \%$ for the PPAC sample, and the microporosity of the PAC sample showed a distribution of $90.3-92.0 \%$.

Table 2. BET analysis results and the electrical conductivity of activated carbon samples.

\begin{tabular}{|c|c|c|c|c|c|c|c|c|c|}
\hline \multirow[b]{2}{*}{ Sample } & \multirow[b]{2}{*}{$\begin{array}{c}\text { Conductivity } \\
\left(\mathrm{Sm}^{-1}\right)\end{array}$} & \multicolumn{5}{|c|}{ BET Analysis } & \multicolumn{3}{|c|}{ Pore Fraction (\%) } \\
\hline & & $\begin{array}{l}S_{B E T} b \\
\left(\mathrm{~m}^{2} / g\right)\end{array}$ & $\begin{array}{c}V_{\operatorname{mi}}{ }^{c} \\
\left(\mathrm{~cm}^{3} \mathrm{~g}^{-1}\right)\end{array}$ & $\begin{array}{c}V_{t}{ }^{d} \\
\left(\mathrm{~cm}^{3} \mathrm{~g}^{-1}\right)\end{array}$ & $\begin{array}{l}V_{2-5} \mathrm{~nm}^{\mathrm{e}} \\
\left(\mathrm{cm}^{3} \mathrm{~g}^{-1}\right)\end{array}$ & $\begin{array}{c}M_{f} f \\
(\%)\end{array}$ & Micropore & Mesopore & Macropore \\
\hline PAC360 & 5.92 & 2659 & 1.25 & 1.38 & 0.08 & 90.3 & 90.3 & 8.3 & 1.4 \\
\hline PAC 380 & 6.55 & 3098 & 1.38 & 1.51 & 0.05 & 91.3 & 91.3 & 7.4 & 1.3 \\
\hline PAC 400 & 5.93 & 2903 & 1.32 & 1.44 & 0.02 & 92.0 & 92.0 & 5.2 & 2.8 \\
\hline PAC420 & 6.44 & 2982 & 1.36 & 1.48 & 0.05 & 91.4 & 91.4 & 5.8 & 2.8 \\
\hline PPAC360 & 4.54 & 2720 & 1.24 & 1.41 & 0.06 & 88.5 & 88.5 & 8.1 & 3.4 \\
\hline PPAC380 & 6.46 & 3133 & 1.35 & 1.53 & 0.08 & 88.6 & 88.6 & 8.5 & 2.9 \\
\hline PPAC400 & 6.25 & 3230 & 1.42 & 1.59 & 0.06 & 89.4 & 89.4 & 10.2 & 0.4 \\
\hline PPAC420 & 7.14 & 3217 & 1.42 & 1.58 & 0.05 & 90.0 & 90.0 & 9.0 & 1.0 \\
\hline
\end{tabular}

${ }^{a}$ Electrical conductivity at $2000 \mathrm{kgf} \mathrm{cm}^{-2}{ }^{\mathrm{b}} \mathrm{S}_{\mathrm{BET}}$ : BET surface area; ${ }^{\mathrm{c}} \mathrm{V}_{\mathrm{mi}}$ : Micropore volume; ${ }^{\mathrm{d}} \mathrm{V}_{\mathrm{t}}$ : Total pore volume; ${ }^{e} V_{2-5} \mathrm{~nm}$ : Pore volume with a size of $2-5 \mathrm{~nm} ;{ }^{f} \mathrm{M}_{\mathrm{f}}$ : Micropore fraction.

In general, the increase in the specific surface area and micropore development of activated carbon appear together, and the activated carbon having a high specific surface area has a large micropore volume [35]. The previous study results revealed that the micropores of a size of less than $2 \mathrm{~nm}$ have low ion accessibility, and thus the capacitance decreases as the micropore volume increases [36]. Another study reported that pores of 
a specific size (2-5 $\mathrm{nm})$ were associated with improved capacitance [37]. Several groups have reported low capacitance measurements of activated carbon with large micropore volumes [38-40].

Figure 2 shows the relationship between the capacitance of the activated carbon electrode and the specific surface area and micropore volume. As shown in Figure 2a, when the specific surface area of the activated carbon increased, the capacitance increased up to about $2600 \mathrm{~m}^{2} \mathrm{~g}^{-1}$ and then decreased. In addition, the micropore volume and specific surface area showed a proportional relationship. Therefore, it is believed that the tendency of the capacitance change is due to the increase in the micropore volume. As the micropore volume increases, the accessible surface area where electrolyte ions can be stored decreases. In addition, as shown in Figure $2 b$, the tendency of decreasing capacitance due to the increase in micropore volume is similar to the change in capacitance according to the specific surface area of Figure 2a. Therefore, the capacitance decreased when the specific surface area of activated carbon increased because the volume of micropores with low electrolyte ion accessibility increased.

(a)

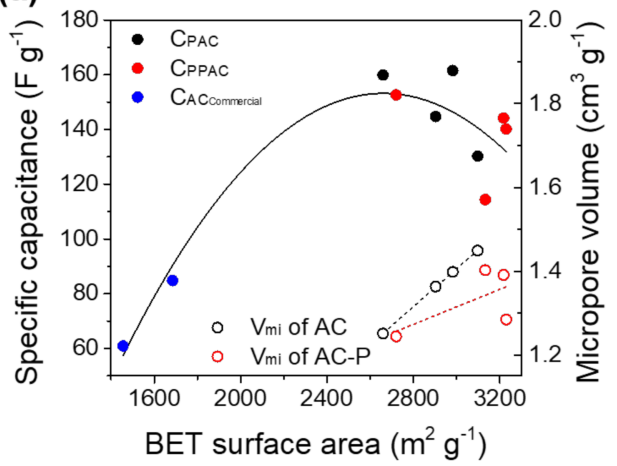

(b)

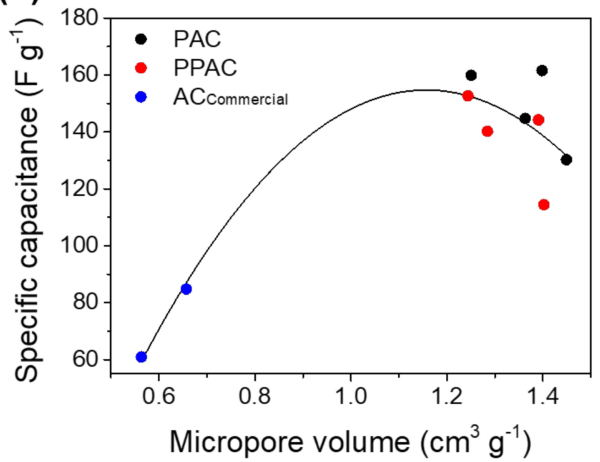

Figure 2. Effect of (a) BET surface area and (b) micropore volume on the specific capacitance of EDLC prepared by various activated carbon samples.

\subsection{Relationship between Pore Distribution and EDLC Capacitance}

The PPAC has a higher specific surface area than PAC but low microporosity. However, the PPAC has a lower capacitance than PAC despite the low porosity. Therefore, it is posited that there is a factor that impedes the storage of ions in pores having a size of $2 \mathrm{~nm}$ or more. The pore size distributions of PAC and PPAC were compared to analyze this factor. Figure 3 shows the $2-5 \mathrm{~nm}$ pore size distribution of PAC and PPAC. All activated carbon had pores distributed around $4 \mathrm{~nm}$, and the PPAC samples developed more pores than PAC. Additionally, PAC360 and PAC420 had pores of about 3.5 and $4 \mathrm{~nm}$ in size, unlike other samples.
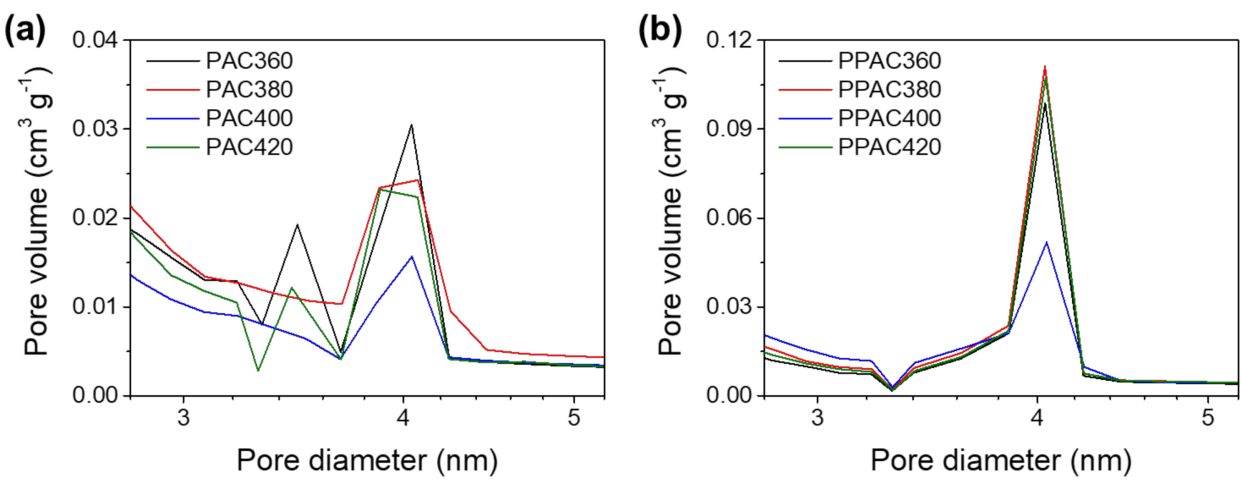

Figure 3. Pore size distribution of (a) PAC and (b) PPAC. 
It should be noted here that the capacitances of PAC360 and PAC420 were higher than those of the other samples. When an electric field is applied to the porous electrode, external ions with opposite charges are electrically adsorbed by the pore surface charge and develop an electric double layer. At this time, when the pore size approaches the thickness of the electric double layer, the electric double layer formed by external ions overlaps. If the size of the micropores is smaller than $2 \mathrm{~nm}$, the EDLC properties are lost due to the overlapping of the electric double layer. In addition, according to the results of previous studies, the development of mesopores, especially $2-5 \mathrm{~nm}$ pores, improves the capacitance [37]. Table 2 shows the volume of $2-5 \mathrm{~nm}$ pores of the activated carbon samples, but it has little correlation with the capacitance measurement. Additionally, the pore volume of $3.5 \mathrm{~nm}$ is insignificant compared to the other activated carbon samples. Therefore, the observation that PAC360 and PAC420 have relatively high capacitance is not due to pores of a specific range or a specific size. To explain this phenomenon, a model of pore structure and ion adsorption behavior is proposed in Figure 4. When two or more peaks appear in the pore size distribution curves, such as in the cases of PAC360 and PAC420, it is determined that pores of different sizes are formed separately, but pores of small sizes are formed inside large pores. In this type of pores, ions are stably stored in small-sized pores at low scan rates, but at fast scan rates, they do not move into smallsized pores. They are stored only in large-sized pores, and, consequently, the difference in capacitance according to the scan rate is significant, as shown in Figure $4 \mathrm{a}$. On the other hand, PPAC shows a narrow mesopore distribution, as shown in Figure $4 \mathrm{~b}$, but, since the pores are well developed, ions can be stably stored even at a fast scan rate, and thus the capacitance is reduced.

\section{(a) PAC at low scan rate}

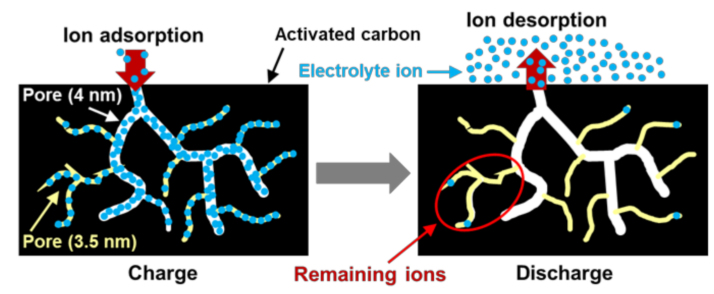

(c) PPAC at low scan rate

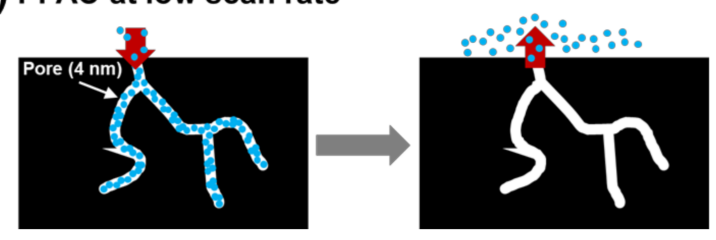

\section{(b) PAC at high scan rate}



(d) PPAC at high scan rate
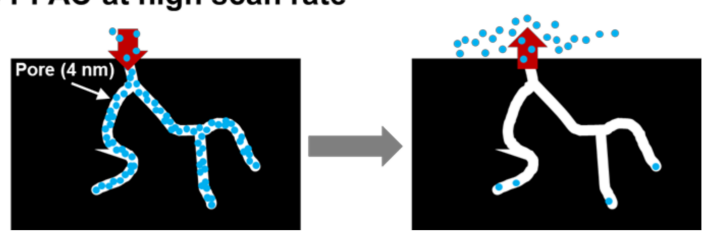

Figure 4. Schematic illustration showing proposed ion storage and expulsion behavior of PAC at (a) a low scan rate and (b) a high scan rate, and that of PPAC at (c) low scan rate and (d) high scan rate.

\subsection{Effect of Conductivity of AC on EDLC Capacitance}

Generally, activated carbons show low conductivity among carbon materials because of their various pore structures, such as micropore $(\sim 2 \mathrm{~nm})$, mesopore $(2 \sim 50 \mathrm{~nm})$, and macropore $(\sim 50 \mathrm{~nm})$. Microporosity (less than $2 \mathrm{~nm}$ ) especially acts as a resistance to charge transfer inside the activated carbon particles, and hence the conductivity decreases as the pore develops. In addition, low electrode density due to pore development makes it difficult to increase electrical conductivity when using activated carbon as an electrode material. In particular, improving the specific surface area of activated carbon in the EDLC reduces the conductivity and electrode density as micropores develop, thereby limiting the improvement of capacitance.

It can be seen from Table 2 that the specific surface area of the pitch-based activated carbon prepared in this study has a high specific surface area of $2500 \mathrm{~m}^{2} \mathrm{~g}^{-1}$ or higher, and micropores are also developed. Therefore, although all samples show low conductivity, 
PPAC tends to exhibit higher conductivity than PAC. To determine the relationship between the microporosity and conductivity, changes in conductivity with the micropore fraction of ACs were investigated. It is generally known that porous carbon materials tend to increase conductivity when the microporosity reduces [7]. However, the conductivity of PAC and PPAC showed a roughly proportional correlation with the micropore fraction in Figure 5a. This result is considered to be due to the oxygen functional groups. Furthermore, several works of research show that the surface functionality of activated carbon significantly affects electrical conductivity [41-44]. Therefore, the conductivity of PAC and PPAC was affected by both microporosity and surface functionality, which interrupts to reveal the correlation of electrical conductivity with micropore property. Furthermore, the electrical conductivity was irrelevant to EDLC capacitance due to the influence of surface oxygen functional groups on the electrical conductivity, as shown in Figure 5b.

(a)

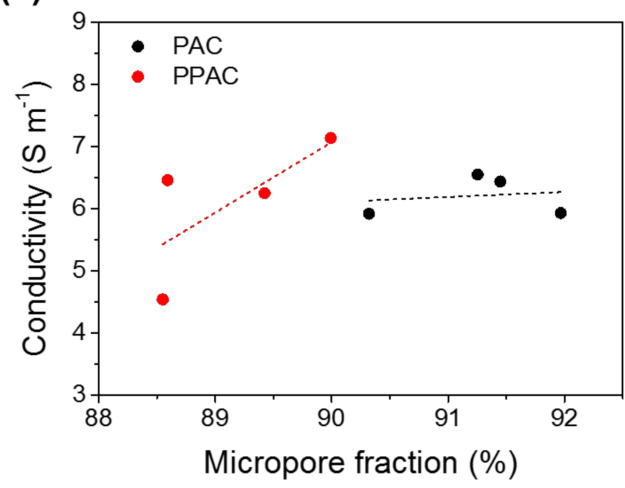

(b)

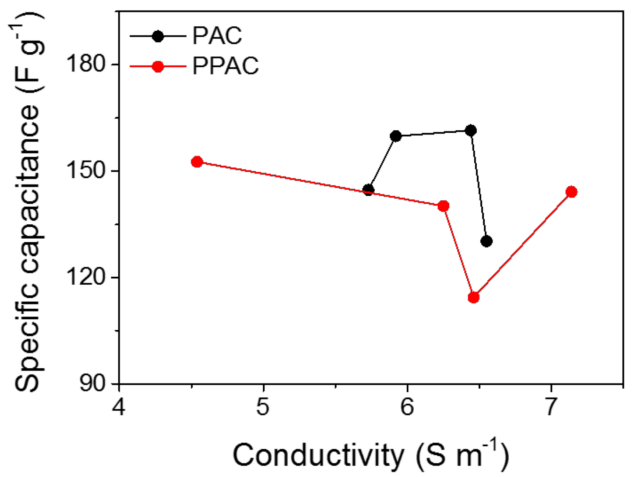

Figure 5. (a) Relationship between the electrical conductivity and micropore fraction of activated carbons with different BET surface areas. (b) Relationship between the specific capacitance and micropore fraction of activated carbons with different electrical conductivities.

In addition, it is observed that PAC360 and PAC400 have relatively high contents of oxygen functional groups in XPS C 1s analysis. Figure 6 shows C 1s spectra of PAC360, PAC380, PAC400, and PAC420 with deconvoluted peaks of $\mathrm{sp}^{2}(284.8 \mathrm{eV}), \mathrm{sp}^{3}(285.2 \mathrm{eV})$, $\mathrm{C}-\mathrm{O}(286.2 \mathrm{eV}), \mathrm{C}=\mathrm{O}(287.6 \mathrm{eV}), \mathrm{O}-\mathrm{C}=\mathrm{O}(289.1 \mathrm{eV})$, and $\pi-\pi^{*}(290.8 \mathrm{eV})$ bonds [45]. The sum of the three oxygen functional groups $(\mathrm{C}-\mathrm{O}, \mathrm{C}=\mathrm{O}$, and $\mathrm{O}-\mathrm{C}=\mathrm{O})$ in PAC360 and PAC400 accounts for 22.4 and $20.5 \%$, respectively, which is higher than that in PAC $380(9.7 \%)$ and PAC420 (8.4\%), as shown in Table 3. It should be noted that the electrical conductivity of PAC360 and PAC400 with a high content of surface oxygen functional groups is relatively higher than that of PAC380 and PAC420, but the micropore fraction of all PAC samples is almost the same as $90.3-92.0 \%$. This is proof that the interparticle charge transfer is inhibited due to the surface oxygen functional groups, resulting in the reduction of electrical conductivity in PAC360 and PAC400.

Table 3. Position and quantitative analysis of XPS C $1 \mathrm{~s}$ peaks.

\begin{tabular}{cccccc}
\hline \multirow{2}{*}{ Bond Component } & \multirow{2}{*}{ Binding Energy (eV) } & \multicolumn{3}{c}{ Percentage of Surface Functional Group (\%) } \\
\cline { 3 - 6 } & & PAC360 & PAC380 & PAC400 & PAC420 \\
\hline $\mathrm{sp}^{2} \mathrm{C}$ & 284.8 & 56.5 & 63.6 & 47 & 64.9 \\
$\mathrm{sp}^{3} \mathrm{C}$ & 285.1 & 18.3 & 23.2 & 27.9 & 23.9 \\
$\mathrm{C}-\mathrm{O}$ & 286.2 & 13.2 & 3.6 & 12.3 & 3.6 \\
$\mathrm{C}=\mathrm{O}$ & 287.6 & 5.4 & 3.6 & 2.3 & 3.3 \\
$\mathrm{O}-\mathrm{C}=\mathrm{O}$ & 289.1 & 3.8 & 3.6 & 4.6 & 2.5 \\
$\pi-\pi^{*}$ & 290.8 & 2.8 & & & \\
\hline
\end{tabular}


(a)

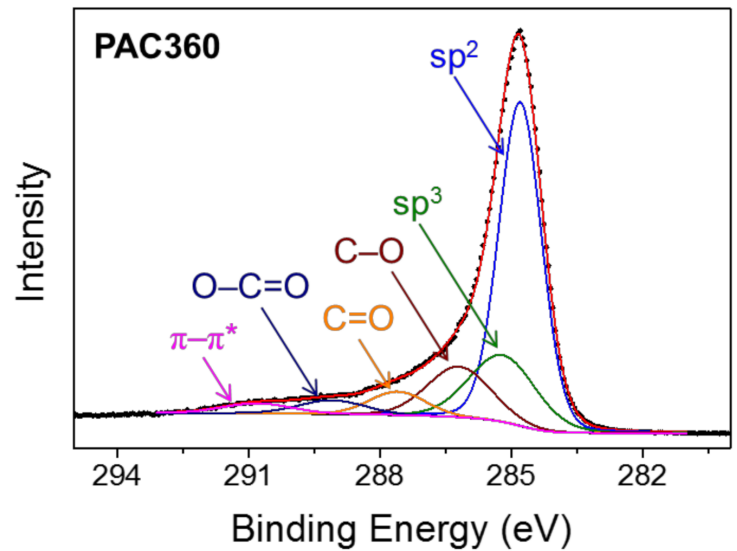

(c)

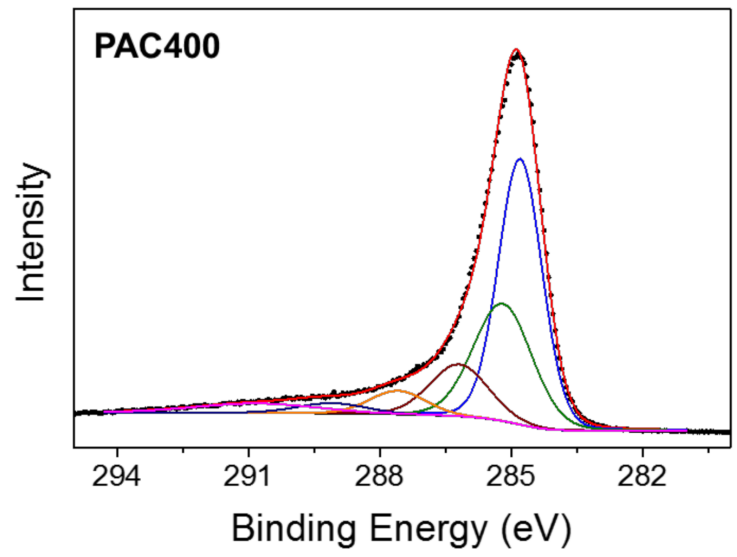

(b)

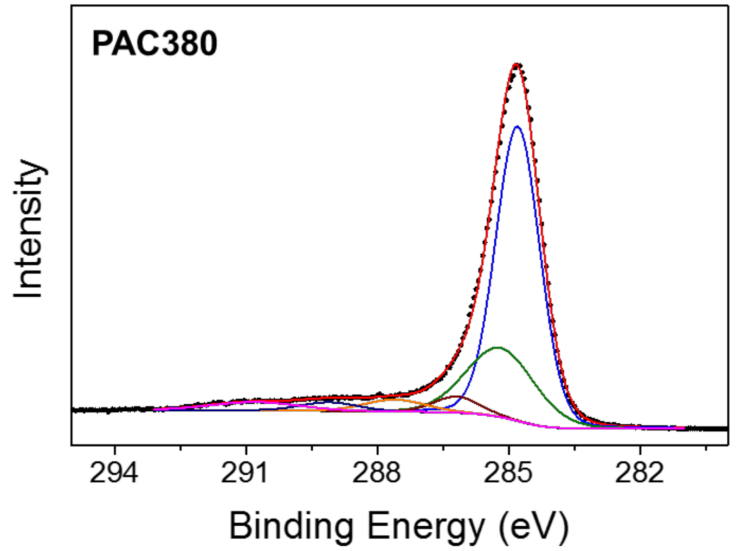

(d)

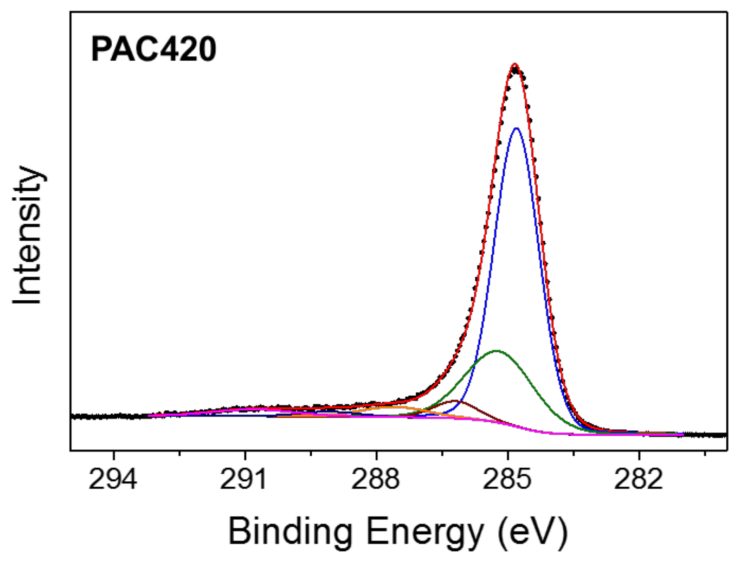

Figure 6. XPS C 1s spectra of (a) PAC360, (b) PAC380, (c) PAC400, and (d) PAC420.

\subsection{Relationship between Capacitance and Physical Properties of AC}

The correlation equation was calculated considering the specific surface area, pore properties, and electrical conductivity of activated carbon to optimize the EDLC capacitance. The equation is indicated below:

$$
\begin{gathered}
y=-6.6 \times 10^{-4} x_{1}{ }^{2}+3.8 x_{1}-4.3 \times 10^{3} x_{2}{ }^{2}+1.1 \times 10^{4} x_{2}-4.5 \times 10^{6} x_{3}{ }^{3} \\
+6.6 \times 10^{5} x_{3}^{2}-2.8 \times 10^{4} x_{3}+30 x_{4}-1.3 \times 10^{4}
\end{gathered}
$$

where $y$ is specific capacitance, $x_{1}$ is specific surface area, $x_{2}$ is micropore volume, $x_{3}$ is mesopore volume at $2-5 \mathrm{~nm}$ pore size, and $x_{4}$ is electrical conductivity. The coefficient of determination $\left(\mathrm{R}^{2}\right)$ is 0.9976 .

The specific surface area and micropore volume are the most influential factors in capacitance. On the other hand, the mesopore volume at $4 \mathrm{~nm}$ pore size and electrical conductivity have a negligible effect on the capacitance. In addition, the capacitance has the highest value when $x_{1}$ and $x_{2}$ are 2879 and 1.28, respectively. In the case of $x_{3}$ and $x_{4}$, the capacitance proportionally decreases and increases, respectively, with their increase. Meanwhile, $x_{3}$ and $x_{4}$ have a negligible effect on the capacitance. Therefore, it is found that only $4 \mathrm{~nm}$ size mesopores are practical for ion storage. The electrical conductivity is affected by another factor, such as surface functionality. The correlation equation determines that the EDLC capacitance is optimized when the surface area and micropore volumes are $2879 \mathrm{~m}^{2} \mathrm{~g}^{-1}$ and $1.28 \mathrm{~cm}^{3} \mathrm{~g}^{-1}$, respectively. 


\section{Materials and Methods}

\subsection{Materials}

PFO (LG Chem, Seoul, Korea) and waste plastic (PET, M.W 48,532, LOTTE Chemical, Seoul, Korea) were used as the raw materials to prepare the pitch. Potassium hydroxide (KOH, 95.0\%, Daejung, Siheung-si, Korea) was used as a chemical activating agent to prepare AC. The products of the activation reaction were neutralized by using $35 \%$ hydrochloric acid ( $\mathrm{HCl}$, Daejung, Siheung-si, Korea) and deionized (DI) water.

\subsection{Pitch Synthesis Using PFO and PET}

For the synthesis of the PFO-based pitch, $500 \mathrm{~g}$ of PFO was placed in a $1 \mathrm{~L}$ reactor and then heated. In the case of the pitch synthesis using PFO and PET, a mixture of $475 \mathrm{~g}$ PFO and $25 \mathrm{~g}$ PET was used. A nitrogen atmosphere was maintained in the reactor by supplying nitrogen gas at a flow rate of $200 \mathrm{~mL} \mathrm{~min}^{-1}$. The pitch was synthesized at 360, 380, 400, and $420{ }^{\circ} \mathrm{C}$. The reactor temperature increased to the synthesis temperature from about heating rate of $2.5^{\circ} \mathrm{C} \mathrm{min}-1$. The reactor was kept for $3 \mathrm{~h}$ at the synthesis temperature and then cooled naturally.

\subsection{Activation of the Pitch Using $\mathrm{KOH}$}

$\mathrm{KOH}^{\prime}$ s activating agent was mixed with a $20 \mathrm{~g}$ pitch with a blender. The weight ratio of pitch to $\mathrm{KOH}$ in the mixture was 1:4. The mixture of pitch and $\mathrm{KOH}$ was activated by putting it into an alumina crucible and inserting the crucible into an electric furnace equipped with a SUS tube. The activation was performed at $800{ }^{\circ} \mathrm{C}$ for $1 \mathrm{~h}$, while the temperature was increased at a rate of $5{ }^{\circ} \mathrm{C} \mathrm{min}^{-1}$. A nitrogen atmosphere was maintained in the interior of the SUS tube by injecting nitrogen gas at a flow rate of $100 \mathrm{~mL} \mathrm{~min}{ }^{-1}$. After completing the activation, the reaction products were neutralized using DI water and $\mathrm{HCl}$ and then rinsed with DI water. The pore volume was calculated from the $\mathrm{N}_{2}$ adsorptiondesorption isotherm obtained by the volumetric gas analyzer (3Flex, Micromeritics). The fraction of pore volume was calculated with the pores of less than $3500 \AA$ diameter.

Pitch-based ACs prepared using only PFO synthesized at 360, 380, 400, and $420{ }^{\circ} \mathrm{C}$ were denoted as PAC360, PAC380, PAC400, and PAC420. In addition, pitch-based AC prepared by adding PET under the same temperature conditions was also prepared, and the samples were denoted as PPAC360, PPAC380, PPAC400, and PPAC420.

\subsection{Preparation and Electrochemical Analysis of EDLC}

As-prepared ACs and two commercial ACs (YP-50F and YP-80F, Kuraray Co., Ltd., Tokyo, Japan) were used as active materials. The sizes of all AC samples were controlled by less than $20 \mu \mathrm{m}$ by using a sieve to fabricate the electrode. The active material, carbon black (Super P, Timcal, Bodio, Switzerland) as a conductive material, and polyvinylidene fluoride (PVDF, Sigma-Aldrich, St. Louis, MO, USA) as a binder were mixed in N-methyl2-pyrrolidone (NMP, Sigma-Aldrich, St. Louis, MO, USA) with a mass ratio of 9:1:1, respectively. A slurry was prepared from the mixture using a Thinky mixer (10 min at $2000 \mathrm{rpm}$ and $10 \mathrm{~min}$ at $2200 \mathrm{rpm}$ ). This slurry was uniformly coated on a current collector of carbon paper (about $150 \mu \mathrm{m}$ in thickness) using a doctor blade apparatus (gap $450 \mu \mathrm{m}$ ) and dried in a vacuum oven at $120^{\circ} \mathrm{C}$ for $12 \mathrm{~h}$. The mass loading of active materials was measured from 14.8 to $18.0 \mathrm{mg} \mathrm{cm}^{-2}$.

The electrochemical analysis of the EDLC based on the AC electrode was carried out in a three-electrode cell. The AC electrode (working electrode) with a $19 \mathrm{~mm}$ diameter, the graphite block (counter electrode), and the $\mathrm{Hg} / \mathrm{HgO}$ reference electrode were equipped in the three-electrode cell filled with the $6 \mathrm{M} \mathrm{KOH}$ electrolyte. The three-electrode cell was connected to the potentiostat instrument to analyze the electrochemical property. 


\subsection{Characterization}

The nitrogen adsorption and desorption isotherms were obtained using a specific surface area measurement instrument (Micromeritics 3Flex instrument). The specific surface area $\left(\mathrm{S}_{\mathrm{BET}}\right)$ and the total pore volume $\left(\mathrm{V}_{\mathrm{T}}\right)$ were calculated from the isotherms. The samples were pre-treated in a vacuum oven at $200{ }^{\circ} \mathrm{C}$ for $8 \mathrm{~h}$, and the specific surface area was measured at $77.3 \mathrm{~K}$ through nitrogen adsorption and desorption. The specific surface area was measured using the multipoint BET method, and the micropore volume $\left(\mathrm{V}_{\text {mic }}\right)$ was calculated using the t-plot method. An electrochemical characterization instrument (ZIVE SP2, WonATech, Seoul, Korea) was used for the cyclic voltammetry (CV) analysis of the EDLC. The CV curve was measured in the potential window from -1.0 to $-0.2 \mathrm{~V}$, with various scan rates from 5 to $100 \mathrm{mV}$. The specific capacitance of EDLC was calculated based on the result of the CV curve. The electrical conductivity of the AC powder was measured using a powder resistivity measurement system (HPRM-FA2, Hantech, Ulsan, Korea). A four-electrode cell with $1 \mathrm{~cm}^{2}$ was filled with $15 \mathrm{~g}$ of AC powder. The resistance of AC powder was measured while applying a pressure of $2000 \mathrm{kgf} \mathrm{cm}^{-2}$ to the cell. The conductivity was calculated using the measured resistance and the cell volume.

\section{Conclusions}

It is known that the specific surface area, micropore volume, mesopore volume at 2-5 nm, and electrical conductivity of activated carbon affect the EDLC capacitance. However, a comprehensive relation between these physical properties of activated carbon is still not well established. Therefore, in this study, the correlation between the EDLC capacitance and the physical properties of activated carbon was investigated, and a correlation equation was determined to optimize the specific surface area and micropore volume to enhance the capacitance. According to the correlation equation, the optimized specific surface area and micropore volumes were $2879 \mathrm{~m}^{2} \mathrm{~g}^{-1}$ and $1.28 \mathrm{~cm}^{3} \mathrm{~g}^{-1}$, respectively.

In addition, activated carbon was prepared using petroleum-based pitch synthesized using PFO with PET addition. It was observed that the EDLC capacitance slightly declined as the scan rate increased from 5 to $100 \mathrm{mV} \mathrm{s}^{-1}$ when the electrode was fabricated with PPAC. This result was obtained due to activated carbon's $4 \mathrm{~nm}$ size mesopores. The mesopores at a $4 \mathrm{~nm}$ size of PPAC were more developed than PAC. As shown in Figure A1, it is strongly contended that this size of mesopore volume effectively enables ion storage.

This study, therefore, provides insight for the development of EDLCs with high capacitance based on an activated carbon electrode, and the physical properties of the activated carbon are optimized. Furthermore, a mechanism of ion storage based on various pore characteristics is proposed.

Author Contributions: Conceptualization, C.H.K. and B.C.B.; methodology, C.H.K., D.K. and B.C.B.; writing-original draft preparation, C.H.K.; writing-review and editing, D.K. and B.C.B.; supervision, B.C.B.; funding acquisition, D.K. All authors have read and agreed to the published version of the manuscript.

Funding: This research was funded by the Korea Evaluation Institute of Industrial Technology (KEIT) through the Carbon Cluster Construction Project, grant number 10083623.

Acknowledgments: This research was supported by the Korea Evaluation Institute of Industrial Technology (KEIT) through the Carbon Cluster Construction Project 10083623. Evaluation of the properties standardization and reliability certification of the carbon materials and intermediate goods.

Conflicts of Interest: The authors declare no conflict of interest. 


\section{Appendix A}

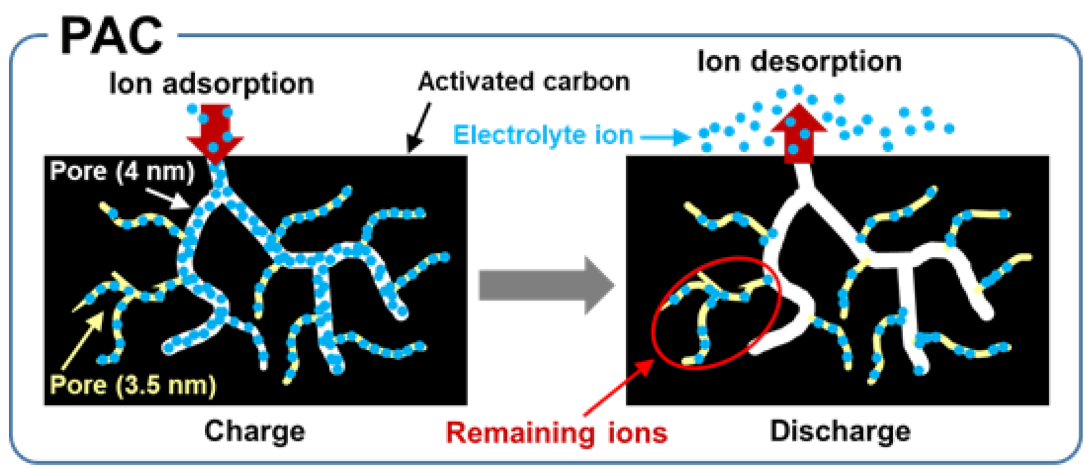

AC: Activated carbon prepared by PFO-based pitch

\section{PPAC}

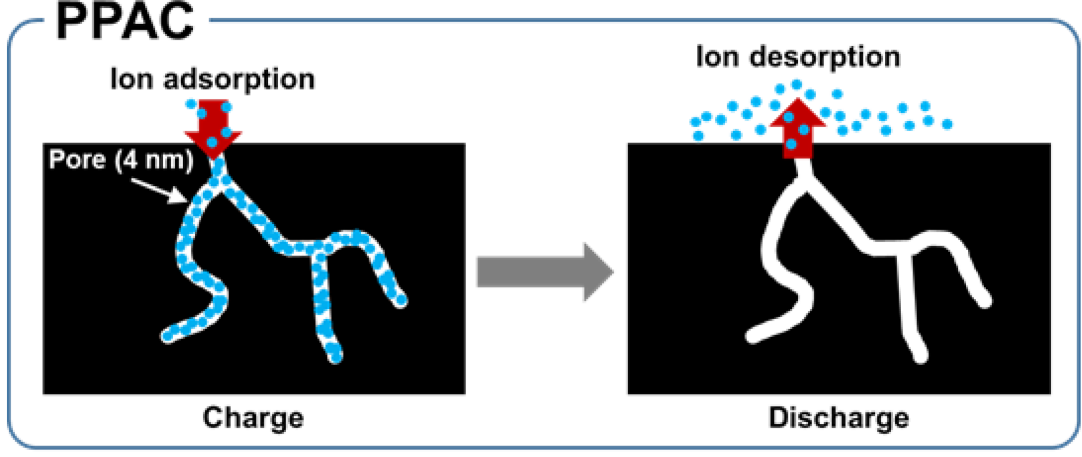

AC-P: Activated carbon prepared by PFO/PET-based pitch

Figure A1. Schematic illustration showing proposed ion storage and expulsion behavior of PAC and PPAC samples.

\section{References}

1. Zhang, C.; Wei, Y.; Cao, P.; Lin, M. Energy Storage System: Current Studies on Batteries and Power Condition System. Renew. Sustain. Energy Rev. 2018, 82, 3091-3106. [CrossRef]

2. Divya, K.C.; Østergaard, J. Battery Energy Storage Technology for Power Systems-An Overview. Electr. Power Syst. Res. 2009, 79, 511-520. [CrossRef]

3. Zu, C.; Li, H. Thermodynamic Analysis on Energy Densities of Batteries. Energy Environ. Sci. 2011, 4, 2614-2624. [CrossRef]

4. Pandolfo, A.; Hollenkamp, A. Carbon Properties and Their Role in Supercapacitors. J. Power Sources 2006, 157, 11-27. [CrossRef]

5. Hong, M.S.; Lee, S.H.; Kim, S.W. Use of KCl Aqueous Electrolyte for 2 V Manganese Oxide/Activated Carbon Hybrid Capacitor. Electrochem. Solid-State Lett. 2002, 5, A227-A230. [CrossRef]

6. Chang, J.; Gao, Z.; Wang, X.; Wu, D.; Xu, F.; Wang, X.; Guo, Y. Activated Porous Carbon Prepared from Paulownia Flower for High Performance Supercapacitor Electrodes. Electrochim. Acta. 2015, 157, 290-298. [CrossRef]

7. Pohlmanna, S.; Lobatob, B.; Centeno, T.A.; Balducci, A. The influence of pore size and surface area of activated carbons on the performance of ionic liquid based supercapacitors. Phys. Chem. Chem. Phys. 2013, 15, 17287-17294. [CrossRef]

8. Zhang, L.; Zhao, X. Carbon-Based Materials as Supercapacitor Electrodes. Chem. Soc. Rev. 2009, 38, 2520-2531. [CrossRef]

9. Yang, K.L.; Ying, T.Y.; Yiacoumi, S.; Tsouris, C.; Vittoratos, E.S. Electrosorption of Ions from Aqueous Solutions by Carbon Aerogel: An Electrical Double-Layer Model. Langmuir 2001, 17, 1961-1969. [CrossRef]

10. Barbieri, O.; Hahn, M.; Herzog, A.; Kötz, R. Capacitance limits of high surface area activated carbons for double-layer capacitors. Carbon 2005, 43, 1303-1310. [CrossRef]

11. Mitani, S.; Lee, S.I.; Saito, K.; Korai, Y.; Mochida, I. Contrast structure and EDLC performances of activated spherical carbons with medium and large surface areas. Electrochim. Acta 2006, 51, 5487-5493. [CrossRef]

12. Xu, B.; Wu, F.; Su, Y.; Cao, G.; Chen, S.; Zhou, Z.; Yang, Y. Competitive effect of KOH activation on the electrochemical performances of carbon nanotubes for EDLC: Balance between porosity and conductivity. Electrochim. Acta 2008, 53, 7730-7735. [CrossRef]

13. Daffos, B.; Taberna, P.L.; Gogotsi, Y.; Simon, P. Recent Advances in Understanding the Capacitive Storage in Microporous Carbons. Fuel Cells. 2010, 10, 819-824. [CrossRef]

14. Urita, K.; Urita, C.; Fujita, K.; Horio, K.; Yoshida, M.; Moriguchi, I. The ideal porous structure of EDLC carbon electrodes with extremely high capacitance. Nanoscale 2017, 9, 15643-15649. [CrossRef] 
15. Im, J.S.; Woo, S.W.; Jung, M.J.; Lee, Y.S. Improved capacitance characteristics of electrospun ACFs by pore size control and vanadium catalyst. J. Colloid Interface Sci. 2008, 327, 115-119. [CrossRef]

16. Li, Z.; Li, D.; Liu, Z.; Li, B.; Ge, C.; Fang, Y. Mesoporous carbon microspheres with high capacitive performances for supercapacitors. Electrochim. Acta 2015, 158, 237-245. [CrossRef]

17. Wu, F.; Tseng, R.; Hu, C.; Wang, C. Effects of Pore Structure and Electrolyte on the Capacitive Characteristics of Steam-and KOH-Activated Carbons for Supercapacitors. J. Power Sources 2005, 144, 302-309. [CrossRef]

18. Zhang, S.; Shi, X.; Chen, X.; Zhang, D.; Liu, X.; Zhang, Z.; Chu, P.K.; Tang, T.; Mijowska, E. Large-Scale and Low-Cost Motivation of Nitrogen-Doped Commercial Activated Carbon for High-Energy-Density Supercapacitor. ACS Appl. Energy Mater. 2019, 2, 4234-4243. [CrossRef]

19. Simon, P.; Burke, A. Nanostructured carbons: Double-layer capacitance and more. Electrochem. Soc. Interface 2008, 17, 38-44. [CrossRef]

20. Jurewicz, K.; Vix-Guterl, C. Capacitance properties of ordered porous carbon materials prepared by a templating procedure J. Phys. Chem. Solids 2004, 65, 287-293. [CrossRef]

21. Portet, C.; Taberna, P.; Simon, P.; Laberty-Robert, C. Modification of Al current collector surface by sol-gel deposit for carboncarbon supercapacitor applications. Electrochim. Acta 2004, 49, 905-912. [CrossRef]

22. Wang, R.; Han, M.; Zhao, Q.; Ren, Z.; Guo, X.; Xu, C.; Hu, N.; Lu, L. Hydrothermal synthesis of nanostructured graphene/polyaniline composites as high-capacitance electrode materials Ionics for supercapacitors. Sci. Rep. 2017, 7, 44562. [CrossRef]

23. Syarif, N.; Tribidasari, I.A.; Wibowo, W. Binder-less activated carbon electrode from gelam wood for use in supercapacitors. J. Electrochem. Sci. Eng. 2013, 3, 37-45. [CrossRef]

24. Andres, B.; Forsberg, S.; Vilches, A.P.; Zhang, R.; Andersson, H.; Hummelgård, M.; Bäckström, J.; Olin, H. Supercapacitors with graphene coated paper electrodes. Nord Pulp. Pap. Res. J. 2012, 27, 481-485. [CrossRef]

25. Roozbeh, H.; Niya, A.; Daud, W.; Sahu, J.N. Preparation and characterization of activated carbon from apple waste by microwave assisted phosphoric acid. Bio. Resour. 2013, 8, 2950-2966.

26. Liu, D.; Li, M.; Qu, F.; Yu, R.; Lou, B.; Wu, C.; Niu, J.; Chang, G. Investigation on Preparation of Mesophase Pitch by the co-carbonization of Naphthenic Pitch and Polystyrene. Energy Fuels 2016, 30, 2066-2075. [CrossRef]

27. Cheng, X.; Zha, Q.; Zhong, J.; Yang, X. Needle coke formation derived from co-carbonization of ethylene tar pitch and polystyrene. Fuel 2009, 88, 2188-2192. [CrossRef]

28. Cheng, Y.; Yang, L.; Luo, T.; Fang, C.; Su, J.; Hui, J. Preparation and Characterization of Mesophase Pitch via Co-Carbonization of Waste Polyethylene/Petroleum Pitch. J. Mater. Sci. Technol. 2015, 31, 857-863. [CrossRef]

29. Blanco, C.; Santamaria, R.; Bermejo, J.; Menendez, R. A comparative study of air-blown and thermally treated coal-tar pitches. Carbon 2000, 38, 517-523. [CrossRef]

30. Holland, B.J.; Hay, J.N. The thermal degradation of PET and analogous polyesters measured by thermal analysis-Fourier transform infrared spectroscopy. Polymer 2002, 43, 1835-1847. [CrossRef]

31. Samperi, F.; Puglisi, C.; Alicata, R.; Montaudo, G. Thermal degradation of poly(ethylene terephthalate) at the processing temperature. Polym. Degrad. Stab. 2004, 83, 3-10. [CrossRef]

32. Lou, B.; Liu, D.; Duan, Y.; Hou, X.; Zhang, Y.; Li, Z.; Wang, Z.; Li, M. Structural modification of petroleum pitch induced by oxidation treatment and Its Relevance to Carbonization Behaviors. Energy Fuels 2017, 31, 9052-9066. [CrossRef]

33. Seo, S.W.; Choi, Y.J.; Kim, J.H.; Cho, J.H.; Lee, Y.S.; Im, J.S. Micropore-structured activated carbon prepared by waste PET/petroleum-based pitch. Carbon Lett. 2019, 29, 385-392. [CrossRef]

34. Heimböckel, R.; Hoffmann, F.; Fröba, M. Insights into the influence of the pore size and surface area of activated carbons on the energy storage of electric double-layer capacitors with a new potentially universally applicable capacitor model. Phys. Chem. Chem. Phys. 2019, 21, 3122-3133. [CrossRef]

35. Jiang, H.; Yang, L.; Li, C.; Yan, C.; Lee, P.S.; Ma, J. High-Rate Electrochemical Capacitors from Highly Graphitic CarbonTipped Manganese Oxide/Mesoporous Carbon/ Manganese Oxide Hybrid Nanowires. Energy Environ. Sci. 2011, 4, 1813-1819. [CrossRef]

36. Scherdel, C.; Reichenauer, G.; Wiener, M. Relationship between pore volumes and surface areas derived from the evaluation of N2-sorption data by DR-, BET- and t-plot. Micropor. Mesopor. Mater. 2010, 132, 572-575. [CrossRef]

37. Mayes, R.T.; Tsouris, C.; Jr, O.K.; Mahurin, S.M.; Depaoli, W. Hierarchical Ordered Mesoporous Carbon from PhloroglucinolGlyoxal and Its Application in Capacitive Deionization of Brackish Water. J. Mater. Chem. 2010, 20, 8674-8678. [CrossRef]

38. Javaid, A.; Ho, K.K.C.; Bismarck, A.; Steinke, J.H.G.; Shaffer, M.S.P.; Greenhalgh, E.S. Improving the Multifunctional Behaviour of Structural Supercapacitors by Incorporating Chemically Activated Carbon Fibres and Mesoporous Silica Particles as Reinforcement. J. Compos. Mater. 2018, 52, 3085-3097. [CrossRef]

39. Jisha, M.; Hwang, Y.; Shin, J.; Nahm, K. Electrochemical Characterization of Supercapacitors Based on Carbons Derived from Coffee Shells. Mater. Chem. Phys. 2009, 115, 33-39. [CrossRef]

40. Linares-Solano, A.; Lillo-Ródenas, M. NaOH and $\mathrm{KOH}$ for Preparing Activated Carbons Used in Energy and Environmental Applications. J. Energy Envr. Economy 2012, 20, 335.

41. Qu, D.; Shi, H. Studies of Activated Carbons Used in Double-Layer Capacitors. J. Power Sources 1998, 71, 99-107. [CrossRef] 
42. Li, B.; Dai, F.; Xiao, Q.; Yang, L.; Shen, J.; Zhang, C.; Cai, M. Nitrogen-doped activated carbon for a high energy hybrid supercapacitor. Energy Environ. Sci. 2016, 9, 102-106. [CrossRef]

43. Chen, Y.; Zhang, X.; Zhang, D.; Yu, P.; Ma, Y. High performance supercapacitors based on reduced graphene oxide in aqueous and ionic liquid electrolytes. Carbon 2011, 49, 573-580. [CrossRef]

44. Jeong, H.M.; Lee, J.W.; Shin, W.H.; Choi, Y.J.; Shin, H.J.; Kang, J.K.; Choi, J.W. Nitrogen-Doped Graphene for High-Performance Ultracapacitors and the Importance of Nitrogen-Doped Sites at Basal Planes. Nano Lett. 2011, 11, 2472-2477. [CrossRef]

45. Liu, X.; Wang, Y.; Zhan, L.; Qiao, W.; Liang, X.; Ling, L. Effect of oxygen-containing functional groups on the impedance behavior of activated carbon-based electric double-layer capacitors. J. Solid State Electrochem. 2011, 15, 413-419. [CrossRef] 